\title{
THE STRUCTURE OF THE CHROMIC ACID PLATING BATH; THE THEORY OF CHROMIUM DEPOSITION
}

\author{
By Charles Kasper
}

\section{ABSTRACT}

The structure of solutions that are of importance to the theory of chromium deposition from the chromic acid bath was investigated by cryoscopic and conductivity measurements, and absorption spectra. It was shown that the first step in the reduction of chromic acid is the formation of chromium dichromate, $\mathrm{Cr}_{2}\left(\mathrm{Cr}_{2} \mathrm{O}_{7}\right)_{3}$, a strong electrolyte which forms negative molecular ions. This compound is found not to exist in the "green" form. The next product of reduction is the basic chromium chromate, $\mathrm{Cr}(\mathrm{OH})_{3} \cdot \mathrm{Cr}(\mathrm{OH}) \mathrm{CrO}_{4}$. This compound is a colloid, which may exist in relatively acid solutions. If sulphate is present, it forms chromic sulphate only the green form of which exists in chromic acid solutions.

If the basic colloid does not have its electrophoretic velocity reduced, it coats the cathode and prevents further reduction of chromic acid. The beneficial action of the sulphate is caused by the fact that it lowers that velocity by adsorption. The sulphate reaches the cathode film by being transported as a nonreactive positive molecular ion, $\left[\mathrm{Cr}_{4} \mathrm{O}\left(\mathrm{SO}_{4}\right)_{4}\left(\mathrm{H}_{2} \mathrm{O}\right)_{n}\right]^{++}$.

The above theory was confirmed by employing it to correlate facts and principles of chromium plating.

\section{CONTENTS}

I. Introduction

II. Materials and solutions

III. Structure of solutions

1. Pure chromic acid. 355

2. Chromium dichromate

(a) Previous work

(b) Cryoscopic evidence

(c) Conductivity measurements

(d) Absorption spectra......................... 357

3. Highly reduced solutions

4. State of sulphate... 364

5. Conclusions

IV. The theory of chromium deposition 366

1. Survey of theories

2. Possible reduction processes

3. Reactions in the cathode film

4. Action of negative ions, such as sulphate

5. Conclusions

V. Applications of the proposed theory 372

VI. Acklowledgments

VII. Bibliography

\section{INTRODUCTION}

Chromium is electrodeposited commercially from baths containing chromic acid (2 to $4 M$ ), a small amount of sulphate $(0.02$ to $0.05 N)$, and a variable concentration of trivalent chromium (derived from the partial reduction of the chromic acid). No entirely satisfactory explanation has been offered for the mechanism of this process, and in particular for the function of the sulphate. 
The research naturally divided itself into two parts-first, the structure of the initial solution and of any system to which it may. give rise on electrolytic reduction, and, second, the deportment of such systems in an electric field.

By the structure of a solution is meant the type and extent of the linkages existing between the various species present. Two types of such bonds are now recognized (23), ${ }^{1}$ although modern research indicates that an indefinite number may exist (29).

Unless otherwise stated, all strong electrolytes ${ }^{2}$ will be regarded as completely ionized at all concentrations. This characteristic is associated with systems in which only the ionic type of linkage exists.

The structure of the solutions was studied by measuring their freezing point lowerings, conductivities, and absorption spectra. From a consideration of published data on the systems of interest and admittedly similar ones, and from new experimental evidence, a theory of the electrodeposition of chromium has been developed. This theory correlates and explains practically all known facts concerning the process and also permits valid predictions to be made.

\section{MATERIALS AND SOLUTIONS}

A special lot of pure chromic acid was employed which had the composition (on a dry basis) shown in Table 1 . The methods of analysis were the same as those employed by Moore and Blum (26).

TABLE 1.-Composition of chromic acid

\begin{tabular}{|c|c|}
\hline Material & Per cent \\
\hline $\begin{array}{l}\text { Chromic acid }\left(\mathrm{CrO}_{3}\right) \\
\text { Trivalent chromium }\left(\mathrm{Cr}_{2} \mathrm{O}_{3}\right) \\
\text { Sulphate }\left(\mathrm{SO}_{4}\right) \\
\text { Alkali }\left(\mathrm{Na}_{2} \mathrm{O}+\mathrm{K}_{2} \mathrm{O}\right)\end{array}$ & $\begin{array}{r}99.75 \\
.15 \\
.01 \\
.01 \\
.01\end{array}$ \\
\hline Total_.. & 99.93 \\
\hline
\end{tabular}

A number of methods were employed to prepare chromic acid solutions containing trivalent chromium and practically no other substances. Reduction with alcohol gave solutions from which the resultant acetic acid could not be readily removed. By dissolving pure $\mathrm{Cr}_{2} \mathrm{O}_{3}$ (produced by igniting $\mathrm{CrO}_{3}$ ) in strong chromic acid, solutions with compositions corresponding to degrees of reduction up to 20 per cent $^{3}$ were obtainable. Dissolving of basic chromate, calcined at $200^{\circ} \mathrm{C}$., in chromic acid yielded the same result. The more highly reduced solutions were prepared by the addition of concentrated hydrogen peroxide. These will be described and discussed in a subsequent section.

The solutions for the cryoscopic measurements were prepared, as customary, on a weight basis (moles per $1,000 \mathrm{~g}$ of water). Those for the measurement of conductivity and light absorption were prepared

\footnotetext{
1 The numbers in the text here and throughout the text refer to the bibliography at the end of the paper. ${ }^{2}$ In this paper the term electrolyte is used in the same sense as ionogen; that is, a substance which when dissolved in a specified medium produces a conducting solution (which latter is frequently called the "electrolyte").

3 The relative content of trivalent chromium in these solutions may be conveniently expressed in terms of the total chromium content. For example, a solution corresponding to $\mathrm{Cr}_{2}\left(\mathrm{Cr}_{2} \mathrm{O}_{7}\right)_{3}$, chromium dichromate, has one-fourth of its chromium content in the trivalent state, and, hence, represents a solution that is 25 per cent reduced. Similarly, the basic-chromate, $\left(\mathrm{Cr}(\mathrm{OH})_{3} \cdot \mathrm{Cr}(\mathrm{OH}) \mathrm{CrO}_{4}\right.$ represents a reduction of about 67 per cent.
} 
on a volume basis (moles per liter of solution). The stated concentrations of free chromic acid are based on the assumption that the trivalent chromium is present as the dichromate, $\mathrm{Cr}_{2}\left(\mathrm{Cr}_{2} \mathrm{O}_{7}\right)_{3}$. Sulphate was introduced as dilute sulphuric acid, which was added at room temperature, and, therefore, produced no appreciable beating.

\section{STRUCTURE OF SOLUTIONS}

\section{PURE CHROMIC ACID}

The published data analyzed by Abegg (7) show conclusively that chromic acid is a strong acid, which at moderate concentrations exists principally as dichromic acid, $\mathrm{H}_{2} \mathrm{Cr}_{2} \mathrm{O}_{7}$, of which both hydrogens are strongly dissociated. In more concentrated solutions trichromic acid, $\mathrm{H}_{2} \mathrm{Cr}_{3} \mathrm{O}_{10}$, and possibly tetrachromic acid, $\mathrm{H}_{2} \mathrm{Cr}_{4} \mathrm{O}_{13}$, exist. In very dilute solutions the monochromate ions, $\mathrm{HCrO}_{4}^{-}$, and $\mathrm{CrO}_{4}^{-}$, are the principal forms. The content of $\mathrm{CrO}_{4}^{-{ }^{-}}$ions at any finite acid concentration is extremely low.

\section{CHROMIUM DICHROMATE}

As it appeared probable from chemical evidence that the first step in the reduction of chromic acid results in the formation of chromium dichromate, the structure of partly reduced solutions was first investigated.

\section{(a) PREVIOUS WORK}

Some investigators (13), (16), and (19) have considered chromium dichromate as a colloid, while others (22) have regarded it as a very weak electrolyte. In all cases the evidence is unsatisfactory. The principal arguments were based upon ultramicroscopic observations. In order that a colloid be detectable by this means it must possess a certain size, a certain refractive index, and a certain transmittancy. It is difficult to see how scattered (not reflected) light could be observed in such highly absorbing solutions as these, if the dispersoid is not a metal. Some solutions like those previously investigated were examined with the ultramicroscope. From these experiments the conclusion was reached that the variable results (and hence the variable interpretations) were caused by dust. No great weight should be attached to ultramicroscopic observations on these solutions.

In addition to obtaining negative results with the ultramicroscope, Ollard (22) cited the qualitative evidence of the migration of the trivalent chromium toward the cathode in these solutions. This observation does not prove that chromium dichromate is a very weak electrolyte. It might be a strong electrolyte or a lyophilic colloid (a micelle).

\section{(b) CRYOSCOPIC EVIDENCE}

The measurements were made with the usual type of apparatus; in the $1 \mathrm{~F}$ series a platinum resistance thermometer was used, and in the $2 \mathrm{~F}$ series a Beckmann. The results are given in Table 2. 
TABLE 2.-Freezing-point depressions

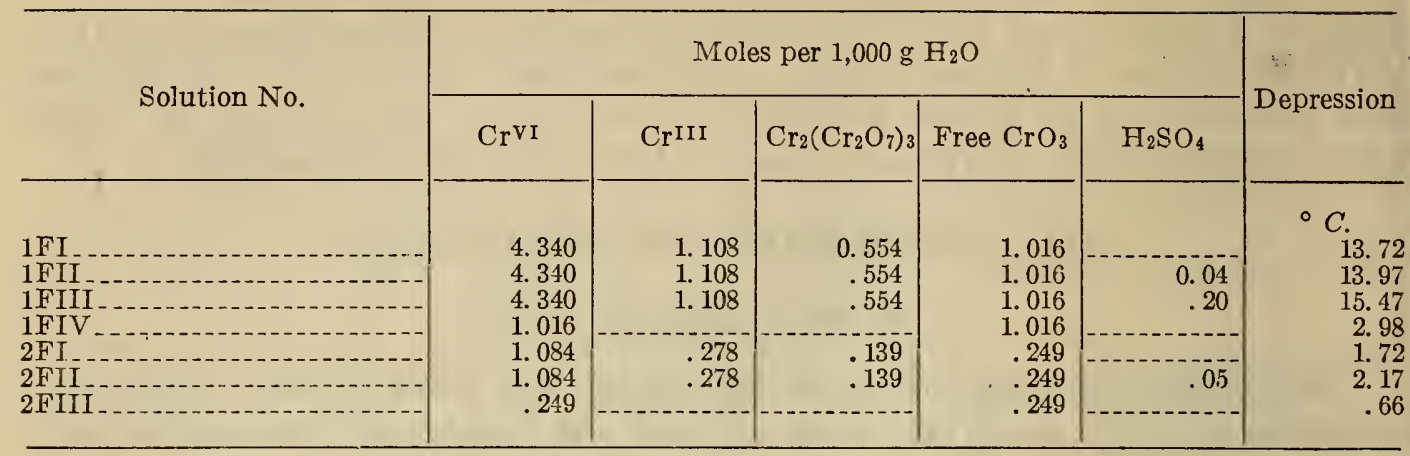

In the designation of a given solution, for example 2FI, the Arabic numeral (2) refers to the apparatus employed, the letter (F) denotes the type of measurement (in this case freezing point), and the Roman numeral (I) refers to the number of the solution in that series. These three symbols define the composition of the solution. Sometimes it was found necessary to heat the solutions for one hour at $100^{\circ} \mathrm{C}$.; such solutions are designated with an additional symbol, B.

The data relating to solutions 1 FI and 1 FIV show that the depression produced by 0.554 mole of chromium dichromate is $13.72^{\circ}-$ $2.98^{\circ}=10.74^{\circ}$, or $19.40^{\circ}$ per mole. If this salt were completely ionized into chromic and dichromate ions, and "perfect" in the Arrhenius sense, there would be a molar depression of $9.3^{\circ}$. The solute is a "superperfect" one, and most certainly is not a colloid or a very weak electrolyte. This point is shown even more conclusively by the data for the more dilute solutions. In the same manner the molal depression calculated from the data for the $0.139 \mathrm{M}$ chromium dichromate is $7.6^{\circ}$; the value for violet chromic sulphate (7) (a comparable solute) at the same dilution is $4.15^{\circ}$.

Heating the above solutions for one hour at $100^{\circ} \mathrm{C}$. caused no change in the depressions. As practically all inorganic chromic compounds exhibit changes in properties (from the violet to the green form ${ }^{4}$ ) when they are heated, this observation is important. This evidence is indicative that the "green" form of chromium dichromate did not exist in these solutions. In this respect this salt is similar to chromic nitrate and perchlorate. The absence of a change in solutions containing sulphate shows that the state of the sulphate is the same in the heated as in the unheated solutions.

\section{(c) CONDUCTIVITY MEASUREMENTS}

A solution that was $1.086 M$ in $\mathrm{Cr}^{\mathrm{vI}}$ and $0.277 M$ in $\mathrm{Cr}^{\mathrm{III}}$, and which was, therefore, $0.255 \mathrm{M}$ in free $\mathrm{CrO}_{3}$, had at $25^{\circ} \mathrm{C}$. a conductivity of $0.666 \mathrm{mho}-\mathrm{cm}$. This is about 15 per cent higher than the interpolated value of 0.579 of Moore and Blum (26) for $0.255 M$ $\mathrm{CrO}_{3}$. The increase in conductivity caused by $0.138 M$ chromium dichromate is $0.086 \mathrm{mho}-\mathrm{cm}$, which corresponds to a molal conductance of $\frac{1,000 \times 0.086}{0.138}=623 \mathrm{mho}-\mathrm{cm}$. The data in Abegg (7) show that the molal conductance of violet chromic sulphate at the same

4 For example, the violet chloride $\left[\mathrm{Cr}\left(\mathrm{H}_{2} \mathrm{O}\right)_{6}\right] \mathrm{Cl}_{3}$, is transformed by heat into the green compound $\left[\mathrm{Cr}\left(\mathrm{H}_{2} \mathrm{O}\right)_{5} \mathrm{Cl}\right] \mathrm{Cl}_{2}$ and $\left[\mathrm{Cr}\left(\mathrm{H}_{2} \mathrm{O}\right)_{4} \mathrm{Cl}_{2}\right] \mathrm{Cl}$. 
dilution is about $800 \mathrm{mho}-\mathrm{cm}$. The difference is of the order expected in view of the greater mobility of the sulphate ion $\left(\mu_{\infty}=136\right)$ as compared with the dichromate ion $\left(\mu_{\infty}=50\right)$.

The cryoscopic and conductimetric measurements that we have made indicate that chromium dichromate is similar in structure to violet chromic sulphate; that is, it is an electrolyte that does not form molecules or molecular ions that include the negative radical. The spectrophotometric measurements to be described indicate that, while this conclusion is in the main correct, true molecular ions do exist.

\section{(d) ABSORPTION SPECTRA}

The cells for these measurements were made entirely of glass and were usually $1 \mathrm{~mm}$ thick. Thin cells were necessary on account of the high absorbencies of most of the solutions. The measurements were limited to wave lengths from 500 to $700 \mathrm{~m} \mu$. The $1 \mathrm{P}$ series were measured on a Koenig-Martens visual spectrophotometer. ${ }^{5}$ The $2 \mathrm{P}$ series were executed on a Bausch \& Lomb visual spectrophotometer. Although the accuracy of our measurements with the latter instrument is not quite as high as with the former, the results are sufficiently precise for our purposes.

In expressing the results the nomenclature of the Optical Society of America (12) is followed as closely as possible. The transmittancy, $T$, is equal to $I / I_{0}$, where $I$ is the light intensity through a cell filled with the solution, and $I_{0}$ that through a similar cell filled with the solvent. The absorbency, $A$, is equal to $-\log _{10} T$. Also, $A$ is equal to $\Sigma\left(a_{i} c_{i}\right) 1$, where 1 is the length in centimeters of the path traversed, $c_{i}$ is the concentration of species $i$ in moles per cubic centimeter, and $a_{i}$ is the molal absorbency of $i$. If the values of $a_{i}$ are independent of those of $c_{i}$, the system is said to obey Beer's law.

All measurements were made at about $25^{\circ} \mathrm{C}$. The composition of the solutions upon which spectrophotometric measurements were made is given in Table 3 .

TABLE 3.-Composition of solutions for spectrophotometric measurements

\begin{tabular}{|c|c|c|c|c|c|c|c|c|}
\hline \multirow{2}{*}{ Designation No. } & \multicolumn{8}{|c|}{ Moles per liter } \\
\hline & $\mathrm{CrVI}$ & CrIII & $\begin{array}{l}\text { Free } \\
\mathrm{CrO}_{3}\end{array}$ & AlIII & YIII & $\mathrm{Cr}\left(\mathrm{SO}_{4}\right)_{3 / 2}$ & $\mathrm{Cr}\left(\mathrm{NO}_{3}\right)_{3}$ & $\mathrm{H}_{2} \mathrm{SO}_{4}$ \\
\hline $\begin{array}{l}\text { 1PI } \\
\text { 1PII } \\
\text { 1PIII } \\
\text { 1PIV }\end{array}$ & $\begin{array}{l}1.086 \\
1.086 \\
1.086 \\
1.086\end{array}$ & $\begin{array}{r}0.277 \\
.277 \\
.277 \\
\end{array}$ & $\begin{array}{r}0.254 \\
.254 \\
.254 \\
1.086\end{array}$ & (n) & - & $\begin{array}{l}-\cdots \\
-\cdots \\
-\cdots\end{array}$ & & $\begin{array}{r}0.01 \\
.10 \\
\end{array}$ \\
\hline $\begin{array}{l}\text { 1PV } \\
\text { 1PVI } \\
\text { 1PVII } \\
\text { 2PI }\end{array}$ & .254 & & .254 & & 0.277 & 0.066 & 0.544 & \\
\hline $\begin{array}{l}2 \mathrm{PII} \\
2 \mathrm{PIII}- \\
2 \mathrm{PIV} \\
2 \mathrm{PV}\end{array}$ & $\begin{array}{l}1.086 \\
.0225 \\
.518 \\
.255\end{array}$ & $\begin{array}{l}.00519 \\
.277 \\
.185\end{array}$ & $\begin{array}{l}.254 \\
.00635 \\
0.0\end{array}$ & 0.277 & & & & \\
\hline
\end{tabular}

${ }^{6}$ These measurements were made by Mabel E. Brown, of the colorimetry section.

132919-32-66 
The first five solutions (and the corresponding heated ones) were so selected that the following salient facts could be determined: First, the absorbency of $\mathrm{Cr}_{2}\left(\mathrm{Cr}_{2} \mathrm{O}_{7}\right)_{3}$ as such; second, the apparent absorbency of $\mathrm{Cr}^{\mathrm{III}}$; third, the possible existence of the "green"

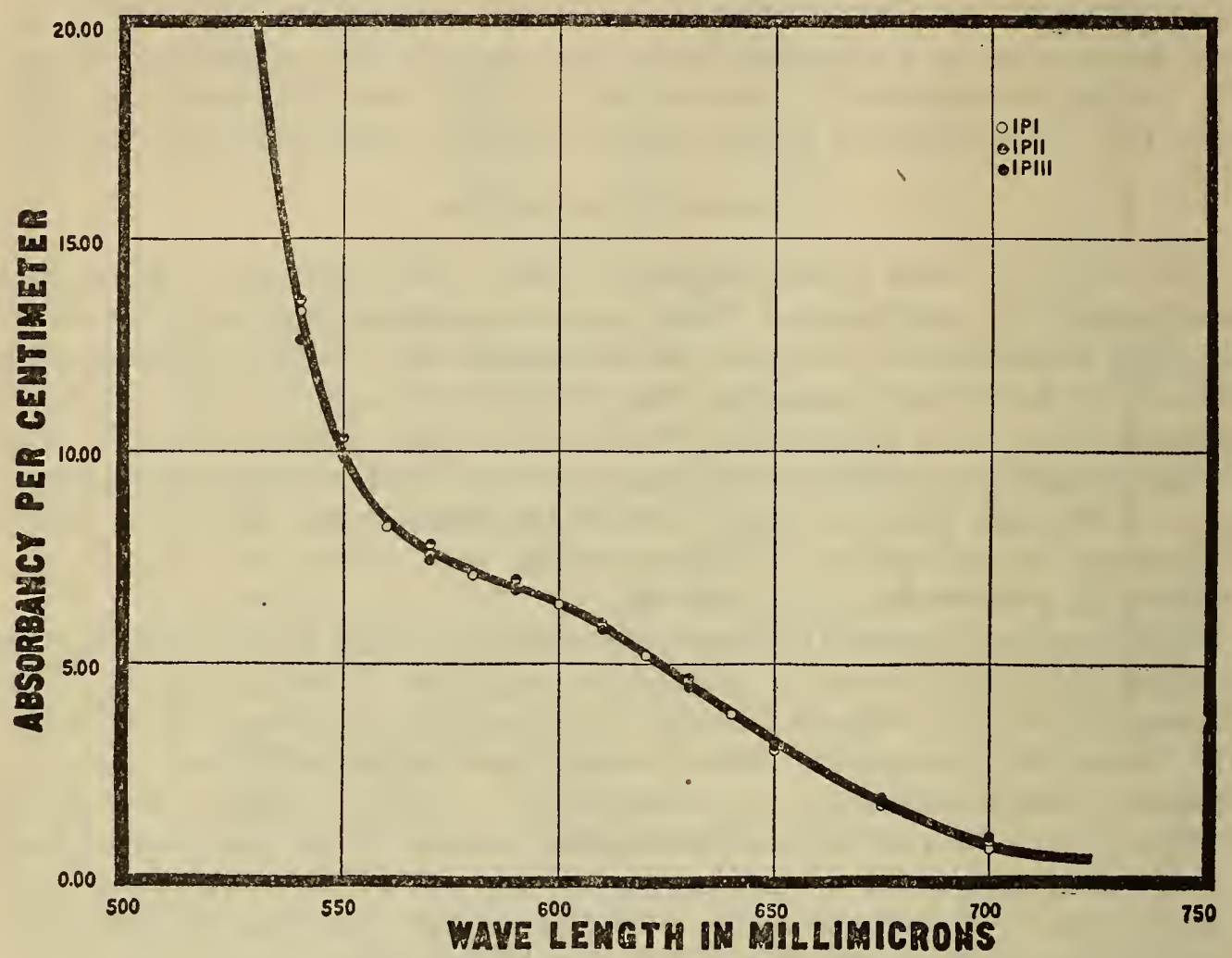

FIGURE 1.-Effect of sulphuric acid on absorbency of solutions containing free chromic acid $(0.254 M)$ and chromium dichromate $(0.139 \mathrm{M})$

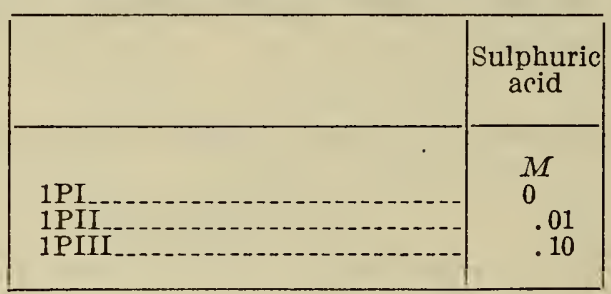

form of chromium dichromate; fourth, the state of the sulphate in cold solutions; and fifth, the state of the sulphate in heated solutions. The data are reported in Table 4 and are plotted in Figures 1, 2, and 3 . 


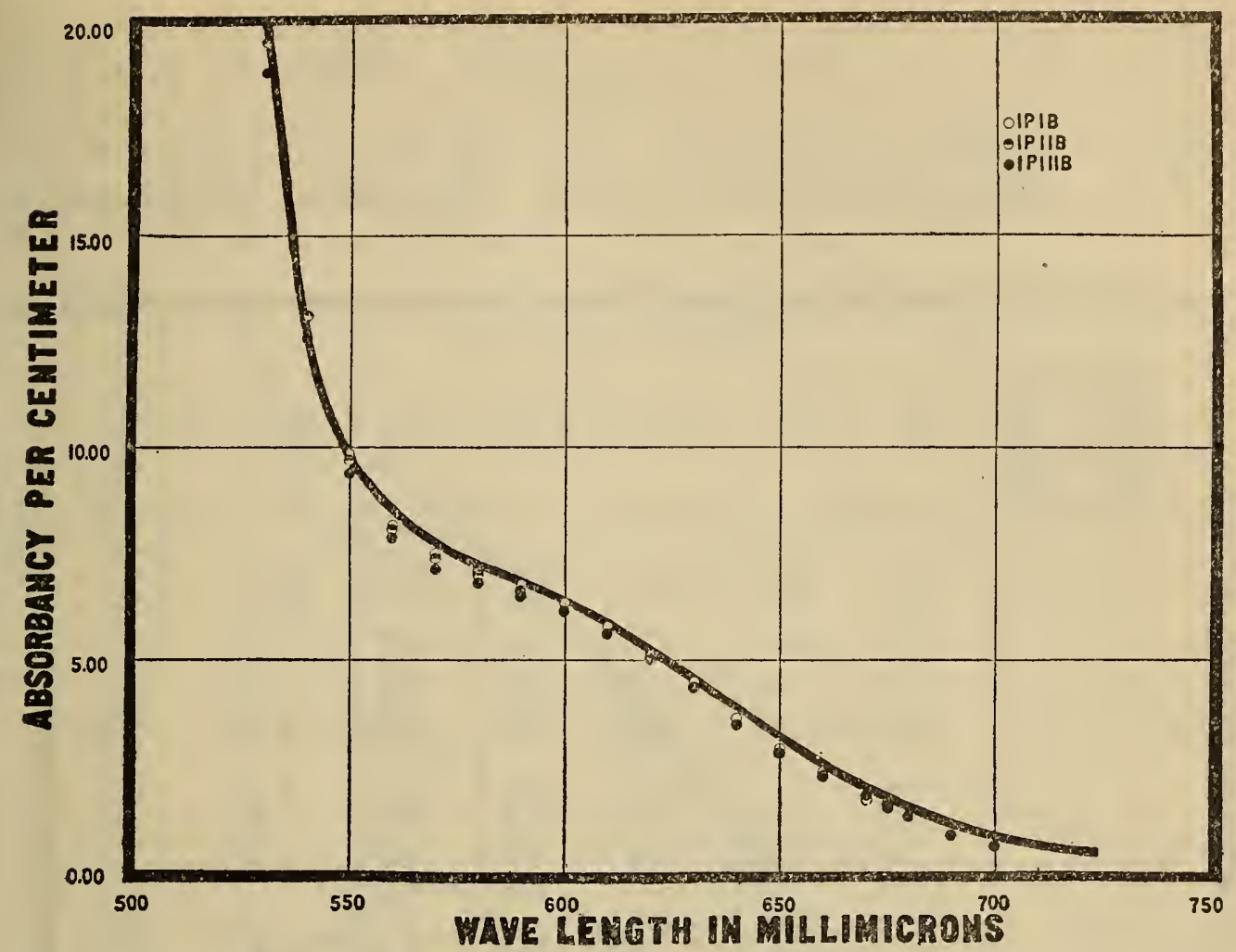

FIGURE 2.-Effect on absorbency produced by heating solutions of Figure 1 to $100^{\circ}$ C. for one hour

(Curve same as in fig. 1)

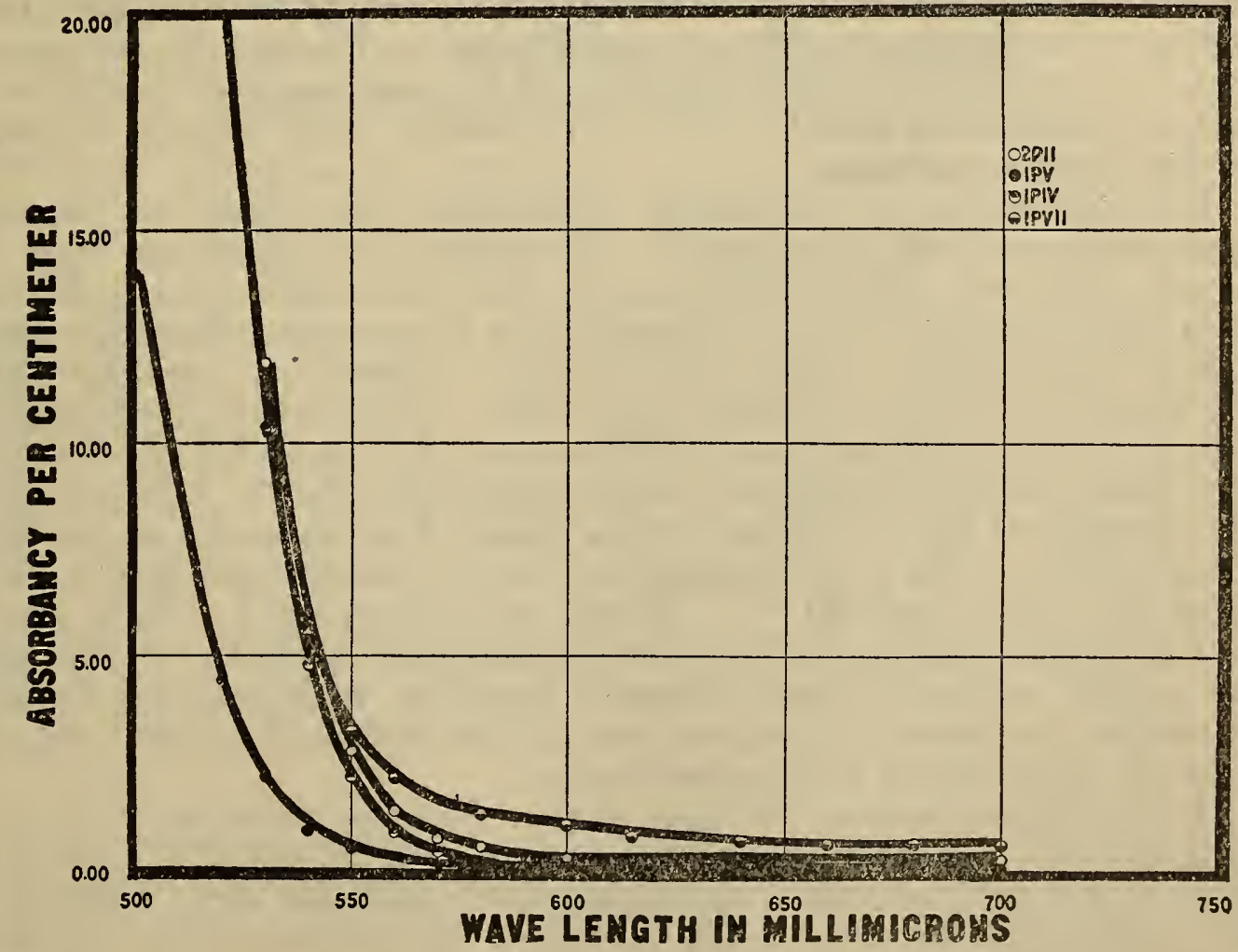

Figure 3.-Effect of trivalent ions on absorbency of chromic acid 


\begin{tabular}{|c|c|c|c|}
\hline & $\mathrm{CrO}_{3}$ & Addition & $M$ \\
\hline $\begin{array}{l}1 \mathrm{PIV}- \\
1 \mathrm{PV}\end{array}$ & $\begin{array}{r}1.086 \\
.254\end{array}$ & & \\
\hline $\begin{array}{l}1 \mathrm{PII} \\
1 \mathrm{PVII}\end{array}$ & $\begin{array}{l}.254 \\
.254\end{array}$ & $\frac{\mathrm{A}^{++++}}{Y^{+++}}$ & $\begin{array}{r}0.277 \\
.277\end{array}$ \\
\hline
\end{tabular}

TABLE 4.-Absorbency per centimeter at $25^{\circ} \mathrm{C}$. of chromic acid solutions containing trivalent chromium

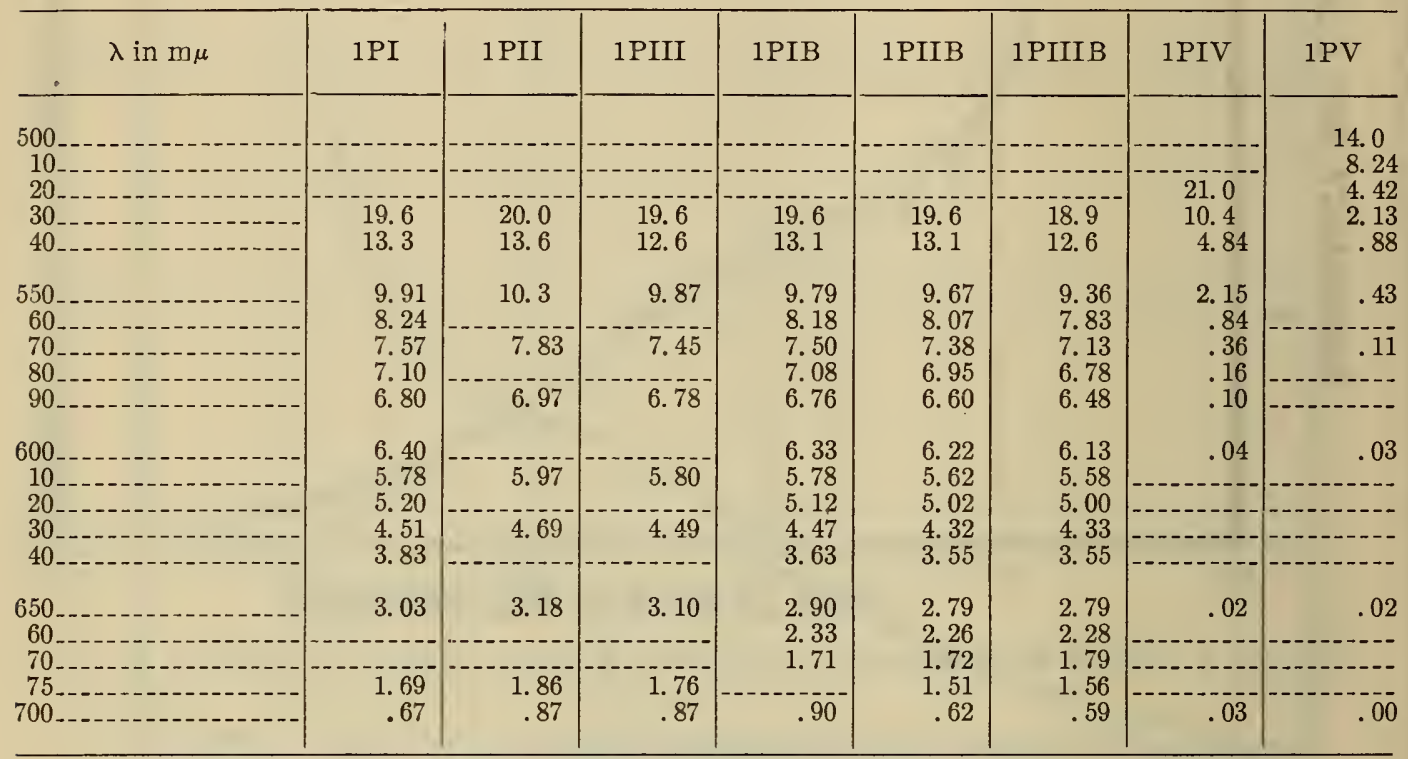

In Figures 1 and 2 it will be noted that there are only small differences due to the sulphate; this point will be discussed in a later section. No significant difference was found on heating the solutions such as. would indicate the formation of a green form of the dichromate. The process would result in an increased absorption in the red by the heated solutions.

The absorbency of chromium dichromate was found to be an unsatisfactory mode of approach. If chromium dichromate were a simple violet salt, subtraction of curve 1PIV from 1PI (which differs from 1 PIV by $0.277 M \mathrm{Cr}^{\mathrm{III}}$ ) should give values approximately onehalf of those of $1 P V I\left(0.554 M \mathrm{Cr}\left(\mathrm{NO}_{3}\right)_{3}\right)$. However, it will be seen in Figure 4 that this is far from being true. This discrepancy is made even worse by correcting for the difference in hydrogen ion concentration, which would change the concentration of $\mathrm{Cr}_{3} \mathrm{O}_{10}{ }^{--}$. Bjerrum (3) has shown that the absorbency of the violet chromic ion is practically independent of the concentration and of the charge and size of the anion $\left(\mathrm{Cl}^{-}, \mathrm{NO}_{3}{ }^{-}\right.$, and $\left.\mathrm{SO}_{4}{ }^{--}\right)$. This is to be interpreted as indicating that the water "molecules" of the molecular ion, $\mathrm{Cr}\left(\mathrm{H}_{2} \mathrm{O}\right)_{6}{ }^{+++}$; protect the optical electrons from excessive coupling with external fields. Therefore, the above discrepancy can not be explained on the basis of a simple deformation of the chromic ion.

Hantszch and Garrett (5) have shown that the absorbency of the chromate ion is greatly affected by the size and charge of the cation. Data on the dichromates of the alkali metals indicate slight deformation, but this possiblity can not be ignored when salts of high valence types are involved. To obtain the desired information regarding deformation of the dichromate ion, the absorbencies of solutions 
2PII and 1PVII were measured. In each there is exactly the same content of hexavalent chromium as in 1 PIV, but 2 PII contains aluminum and 1PVII yttrium, each in a concentration equivalent to that of trivalent chromium in 1PI. The data are reported in Table 5, and are plotted in Figure 3. Table 5 also includes solutions that will be discussed later in this paper.

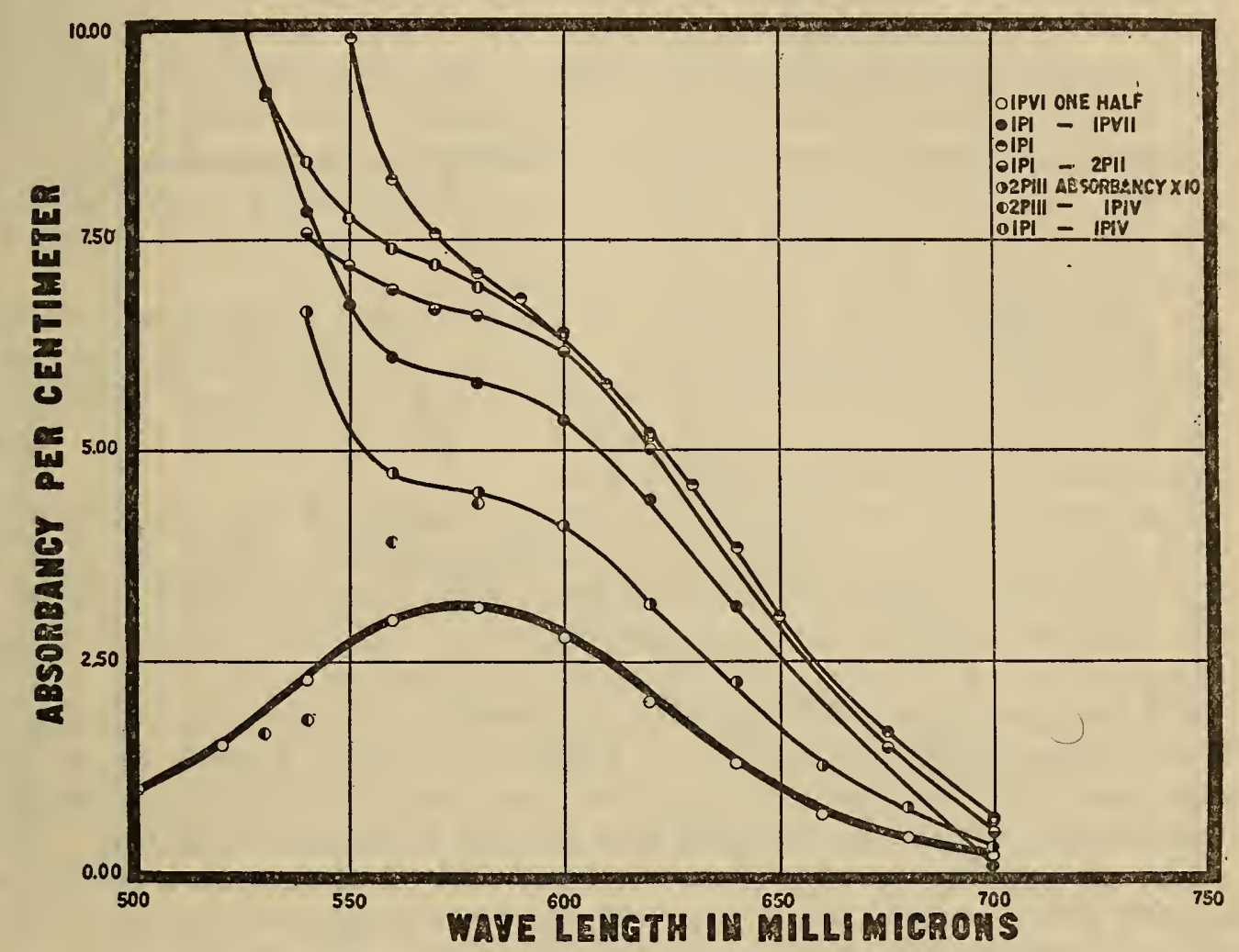

FigdRE 4.-Absorbencies of various chromium solutions

TABLE 5.-Absorbency per centimeter of various chromium solutions at $25^{\circ} \mathrm{C}$.

\begin{tabular}{|c|c|c|c|c|c|}
\hline$\lambda$ in $\mathrm{m} \mu$ & $2 \mathrm{PI}$ & 2PII & 2PIII 1 & 1PVI & 1PVII \\
\hline 500 & 0.67 & & & 1.95 & \\
\hline $20 \ldots$ & & & & 3.05 & 19.6 \\
\hline 40 & .97 & $\begin{array}{c}11.9 \\
5.68\end{array}$ & $\begin{array}{r}12.00 \\
6.64\end{array}$ & 4. 56 & $\begin{array}{r}10.3 \\
5.4\end{array}$ \\
\hline $\begin{array}{r}550 \\
60 \\
80 \\
600\end{array}$ & 1.31 & $\begin{array}{r}2.73 \\
1.32 \\
.50 \\
.23\end{array}$ & $\begin{array}{l}\text { 4. } 75 \\
4.50 \\
4\end{array}$ & $\begin{array}{l}5.99 \\
6.35 \\
5.55\end{array}$ & $\begin{array}{l}3.16 \\
2.12 \\
1.30 \\
1.04\end{array}$ \\
\hline $600 \ldots$ & 1.31 & & $\begin{array}{l}\text { 4. } 10 \\
\text { 3. } 19\end{array}$ & $\begin{array}{l}\text {. } \\
\text { 4. } 09\end{array}$ & $\begin{array}{r}1.04 \\
.78\end{array}$ \\
\hline $\begin{array}{l}40- \\
600 \\
80\end{array}$ & 92 & & $\begin{array}{r}2.26 \\
1.28 \\
.79\end{array}$ & $\begin{array}{r}2.63 \\
1.41 \\
.89\end{array}$ & $\begin{array}{l}.67 \\
.62 \\
.60\end{array}$ \\
\hline $700--1$ & 41 & .17 & .38 & .41 & .00 \\
\hline
\end{tabular}

1 Absorbency $\times 10$.

It is well known that in ionic systems deformation effects can be related to the size and charge of the "companionate" ions. Only relative sizes of the bare (not hydrated) ions are involved. The available data indicate that no simple analysis is possible, but it is legitimate to employ the conception for interpolative purposes. 
Crystal structure data (28) indicate that the radii of the trivalent ions of $\mathrm{Al}, \mathrm{Cr}$, and $\mathrm{Y}$ are, respectively, $0.55,0.70$, and $0.90 \mathrm{~A}^{\circ}$. So, from a knowledge of the deformation produced by aluminum and yttrium, we can estimate that to be expected from chromium. The data plotted in Figure 3 show that the deformation is, as demanded by the above discrepancy, greater with the increasing charge $\left(\mathrm{H}^{+}\right.$ (1PIV) to $\mathrm{Al}^{+++}$) and for trivalent ions increases with increasing: radius. The deformation caused by $\mathrm{Cr}^{\mathrm{III}}$, may be assumed to be intermediate between those of $\mathrm{Al}$ and $\mathrm{Y}$ (tbat is, between the curves $1 \mathrm{PI}$ to $2 \mathrm{PII}$ and 1PI to 1PVI). Evidently this deformation by $\mathrm{Cr}^{\mathrm{III}}$ is insufficient to account for the difference in question; that is, between 1PI and one-half 1PVII. Some other mode of interaction than the ionic is evidently effective; that is, the molecular. This is not unusual with chromic compounds (29).

It appears probable, therefore, that chromium dichromate exists as a Werner coordination complex. Its exact nature was not investigated, but the character of the absorption bands indicate that it is $\left[\left(\mathrm{H}_{2} \mathrm{O}\right)_{2} \mathrm{Cr}\left(\mathrm{Cr}_{2} \mathrm{O}_{7}\right)_{2}\right]^{-}$or $\left[\mathrm{Cr}\left(\mathrm{Cr}_{2} \mathrm{O}_{7}\right)_{3}\right]^{---}$. The possibility of a true undissociated molecule is not excluded.

The cryoscopic and conductivity data indicated that this, unlike most coordination complexes, is highly dissociated. If so, it should not obey Beer's law. It is evident from Figure 4 that 2PIII (a fortyfold dilution of $1 \mathrm{PI}$ examined through a $40 \mathrm{~mm}$ cell) shows a large decrease in absorbency. On formally subtracting 1PIV from 2PIII it will be noted that the values at the shorter wave lengths fall below those of the simple chromic ion. This correction is known to be too large, and with further dilution the curve would, no doubt, coincide at the longer wave lengths with that for the simple chromic ion.

The absorption spectra show conclusively that chromium dichromate is not a colloid, as this would have a strong absorbency in the red and would obey Beer's law strictly (34). All experiments were consistent with the interpretation made, and inconsistent with any other that was entertained. No variations in absorbency occurred on standing for long periods.

\section{HIGHLY REDUCED SOLUTIONS}

Ollard (22) reported that by treating chromic acid solutions with concentrated hydrogen peroxide, a reduction up to 50 per cent $\left(\mathrm{Cr}(\mathrm{OH}) \mathrm{CrO}_{4}\right)$ could be effected, but that beyond that point a precipitate of $\mathrm{Cr}(\mathrm{OH})_{3} \mathrm{Cr}(\mathrm{OH}) \mathrm{CrO}_{4}$, (9) (14) (67 per cent reduction) was produced. In our experiments it was found that a reduction as high as 60 per cent could be thus effected without immediate precipitation. On standing one or more days the above precipitate appeared in which the ratio of the trivalent to hexavalent chromium was 2 to 1 and the filtrate corresponded to about 37 per cent reduction. The precipitation occurred 'with all solutions more highly reduced than 37 per cent. The rate of precipitation varied directly as the degree of reduction; it was accelerated by heating. These observations indicate that the system is a mixture of a sol, whose dispersoid is $\mathrm{Cr}(\mathrm{OH})_{3} \mathrm{Cr}(\mathrm{OH}) \mathrm{CrO}_{4}$, and a true solution of an electrolyte, chromium dichromate. The reason that solutions with 37 per cent reduction are stable is that then the hydrogen ion concentration is so high that the particles of the basic sol become sufficiently electropositive to remain in suspension. This hypothesis was confirmed by precipitat- 
ing the basic chromate out of partially reduced solutions (42 per cent) with sodium sulphate.

Liebreich (9) and Müller (14) prepared colloidal solutions of the basic chromate by digesting the precipitate with water for a long time. The method employed in the present research was to take an unstable, highly reduced solution and dilute it strongly. Sols prepared in this manner exhibited a strong Tyndall beam and a dichroic appearance. They were quite murky and hence had fairly large particles, though none were visible with the ultramicroscope. As previously noted this instrument is not well adapted for these solutions.

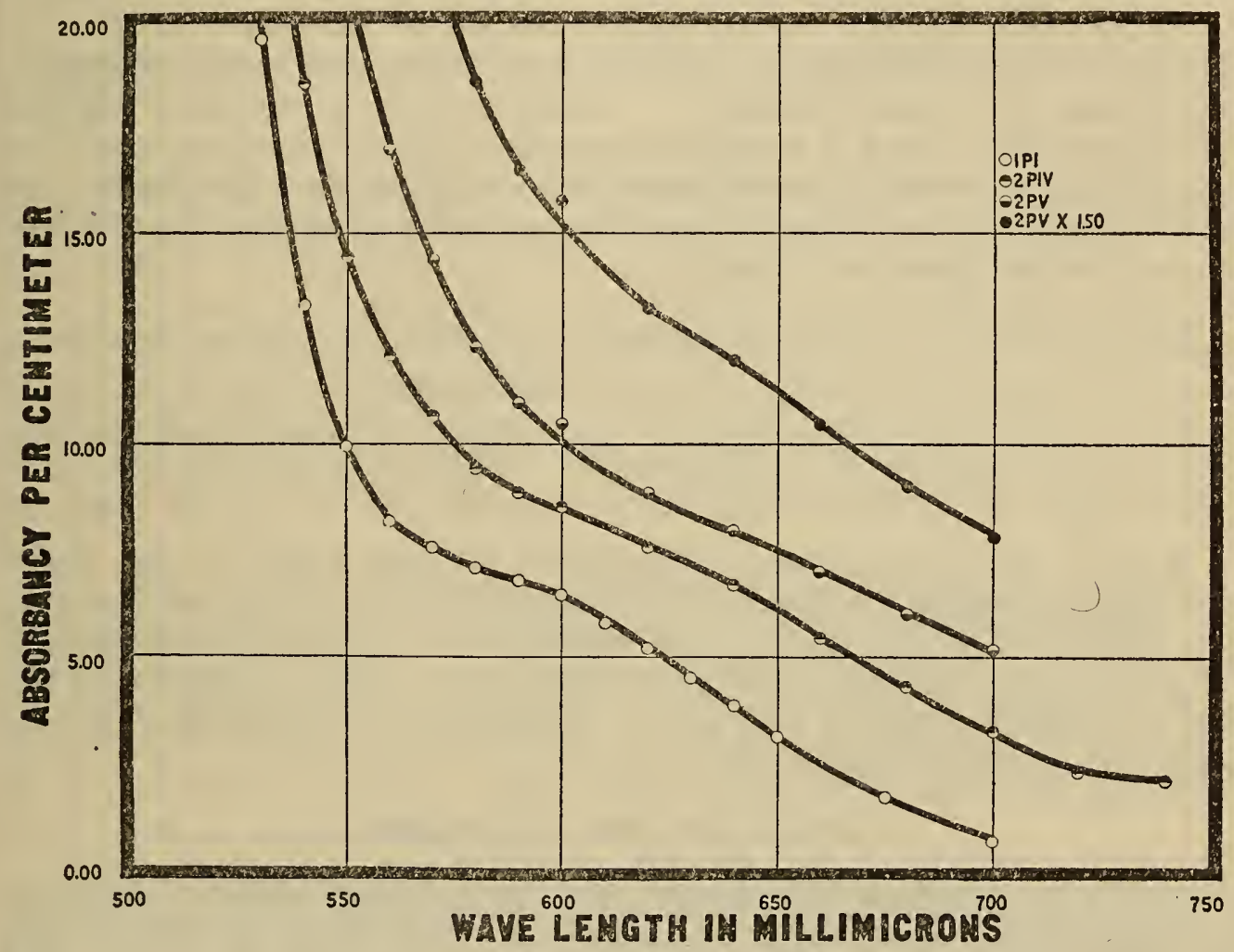

FIGURE 5.-Absorbencies of solutions with equal contents of trivalent chromium and decreasing contents of hexavalent chromium

The absorbency data for the highly reduced solutions, 2PIV and $2 \mathrm{PV}$ (prepared in the cold), are recorded in Table 6 and shown in Figure 5.

TABLE 6.-Absorbency per centimeter of highly reduced solutions

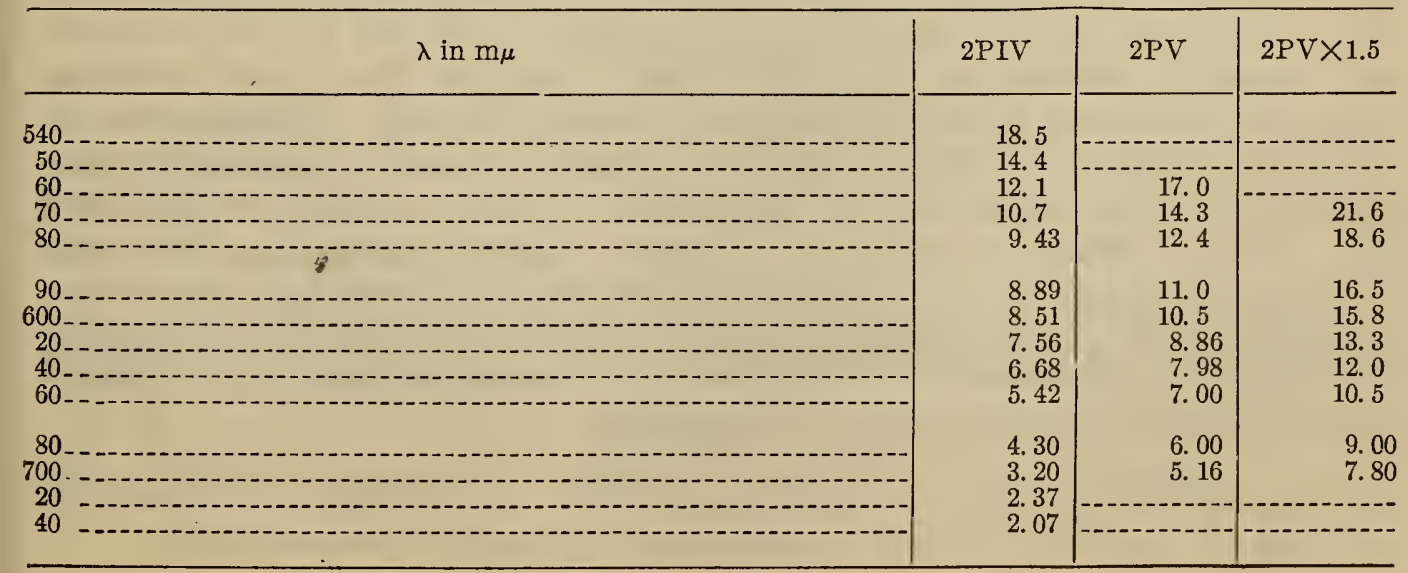


The data in the last column have been recalculated to correspond to the same concentration of trivalent chromium as the other two. It will be noted that an increase in reduction causes an increased absorption over the entire range. The increase at the shorter wave length is probably caused in part by the deformation of the chromate radical. The increase in absorption in the red could be caused either by a complex (green) electrolyte, or a colloid, or both.

An effort to settle the question by freezing point measurements was only partially successful in that the data could be interpreted equally well in terms of a weak electrolyte or a mixture of a strong electrolyte and a colloid. Like the other solutions, these also coagulate, indicating that the latter interpretation is the correct one.

Electrometric methods of titration have a greater range of applicability than the conductimetric. Solutions with a constant content of $\mathrm{Cr}^{\mathrm{VI}}(0.184 \mathrm{M})$ and a variable content of $\mathrm{Cr}^{\mathrm{III}}$ were prepared and their $\mathrm{pH}$ values were determined with a modified glass electrode. In effect, therefore, chromic acid was titrated with chromium hydroxide. The results are given in Table 7.

TABLE 7.-pH of chromic acid $(0.184 M)$ with additions of trivalent chromium

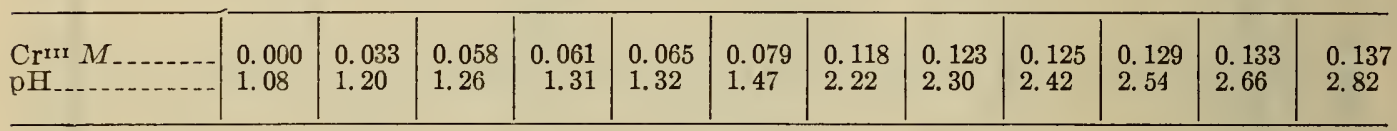

A plot of these data does not indicate a sharp break of any kind. More highly reduced solutions (corresponding to 60 per cent reduction) had a $\mathrm{pH}$ of about 3.5. According to the above interpretation of the structure of this system, we may have large amounts of the basic colloid at a $\mathrm{pH}$ as low as 3 . This point is important for the theory of chromium deposition.

\section{STATE OF THE SULPHATE}

The above recorded cryoscopic and spectrophotometric measurements included some data on solutions containing chromic acid, chromium dichromate, and sulphuric acid. As noted before, the cryoscopic measurements indicated that there was no difference in the state of the sulphate in the heated and unheated solution. This behavior would be impossible with the violet chromic sulphate, so the green salt must be present.

The spectrophotometric measurements confirm this conclusion. It will be noted in Figures 1 and 2 that the absorbencies of the solutions with the largest content of sulphate are lower at the shorter, and (usually) higher at the longer, wave lengths than those with no sulphate, whether the solutions are heated or not. This is to be expected if green chromic sulphate replaces some chromium dichromate. The difference can be calculated ${ }^{6}$ from the data on 1PI and 2 PI, which latter is a solution of green chromic sulphate that was

${ }^{6}$ As this is rather involved, a sample calculation, that at $540 \mu \mu$ is given. According to Table 1 the absorb. ence per centimeter of the chromium dichromate in $1 \mathrm{PI}$ is $13.30-0.88=12.4$. 1PIII contains in addition $0.1 \mathrm{M}$ of sulphate. If the complex is $\left[\mathrm{Cr}_{4} \mathrm{O}\left(\mathrm{SO}_{4}\right)_{4}\left(\mathrm{H}_{2} \mathrm{O}\right)_{n}\right]^{++}$, then according to Tables 3 and 5 the expected absorbency of the green chromic sulphate will be $0.97 \times \frac{3}{2} \cong 1.5$;

There will be a loss in absorbency corresponding to $\frac{1}{2.77} \times 12.4 \cong 4.1$. So the change in absorbency will be $4.1-1.5-1.3=1.3$. The minus 1.3 denotes the increase due to the formation of free chromic acid. 
heated for one hour at $100^{\circ} \mathrm{C}$. The effects, though small, are quite definite and beyond experimental error; the interpretation explains why only a small change is found. The results are given in Table 8.

TABLE 8.-Change in absorbency produced by addition of sulphate to solutions containing $\mathrm{Cr}^{\mathrm{VI}}$ and $\mathrm{Cr}$ III

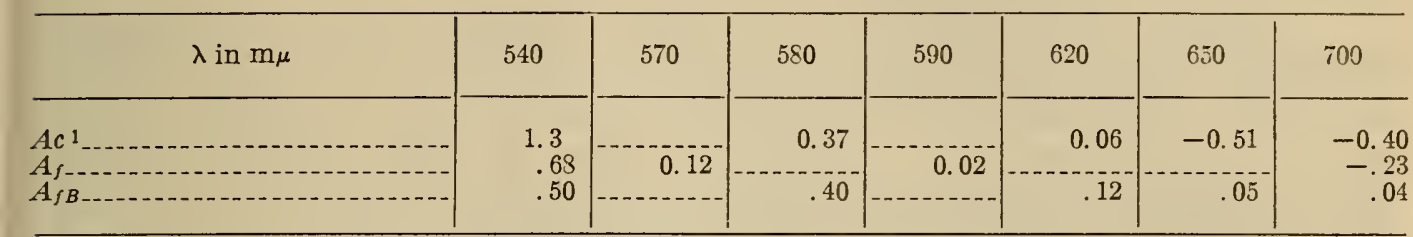

${ }_{1} A_{\mathrm{c}}$ is the calculated change in absorbency, $A_{\mathrm{f}}$ is that found for the unheated series, and $A_{f B}$ that for the heated series.

The green complexes of chromic sulphate possess very remarkable properties. Some are true colloids, but most of them are electrolytes. The colloidal form is obtained only with drastic treatment. Part of the sulphate in the ordinary green forms is combined with the trivalent chromium to form a positive molecular ion $\left[\mathrm{Cr}_{4} \mathrm{O}\left(\mathrm{SO}_{4}\right)_{4}\left(\mathrm{H}_{2} \mathrm{O}\right)_{n}\right]^{++}$. In the green chloride we have $\left[\mathrm{CrCl}\left(\mathrm{H}_{2} \mathrm{O}\right)_{5}\right]^{++}$and $\left[\mathrm{CrCl}_{2}\left(\mathrm{H}_{2} \mathrm{O}\right)_{4}\right]^{+}$. These complexes are remarkable in that apparently there is absolutely no dissociation of the coordinated groups. Electron pair bonds are undoubtedly effective (29). These positive molecular ions furnish an ideal means of conveying the sulphate radical into the cathode film.

The $\mathrm{pH}$ of pure violet chromic sulphate solutions is about 2 . It was noted previously that the maximum $\mathrm{pH}$ found in solutions containing colloidal basic chromium chromate was 3.5. These data indicate that, barring complex formation (which, however, is not favored at a intermediate $\mathrm{pH}$ like 3 ), free sulphate ions can exist in these colloidal solutions. This point is also important for the theory of chromium deposition.

In pure solutions the violet form is the more stable at room temperature and below; the green is more stable above room temperature. The rate of conversion of the green into the violet is low, especially in the presence of acid, which acts as a negative catalyst and may even shift the quasiequilibrium. Such a shift is recorded in this paper for the sulphate in chromic acid solutions; a similar case has been worked out by Bjerrum (2) for violet chromic chloride in hydrochloric acid solutions. The fairly high temperatures employed in chromium deposition probably assist in this shift of equilibrium.

\section{CONCLUSIONS}

1. Chromium dichromate is a strong electrolyte and forms true molecular ions.

2. The "green" form of chromium dichromate does not exist in the solutions investigated.

3. More highly reduced solutions than the dichromate contain, in addition to that compound, a sol of the basic chromium chromate $\mathrm{Cr}(\mathrm{OH})_{3} \mathrm{Cr}(\mathrm{OH}) \mathrm{CrO}_{4}$.

4. In partially reduced solutions with an excess of chromic acid, the sulphate exists principally as the green chromic sulphate. 


\section{THE THEORY OF CHROMIUM DEPOSITION}

\section{SURVEY OF THEORIES}

The principal theories of chromium deposition that have been advanced will be briefly considered, including that proposed by the author in this investigation.

1. Sargent (6) recognized a number of features that are extremely important; that the cathode film is only slightly acid at high current densities, that reduction of chromic acid at high current densities must occur through the medium of the chromic-chromous couple (see p. 369), that sulphate is necessary for metal deposition, and that pure chromic acid can be reduced at low but not at high current densities. The latter feature he attributed to a colloidal layer which he designated as nonpermeable, though he tacitly assumed it to be permeable to hydrogen ions. The mechanism of the action of the sulphate was not clearly set forth.

2. Liebreich (9) (10) measured polarization curves by means of which he endeavored to show the successive stages through which chromic acid must pass before being reduced to the metallic state. The existence of this "step-wise" reduction is the principal feature of Liebreich's theory. The action of the sulphate was not explained. He demonstrated that the cathode film is less acid than the solution, and that in it there probably is an electropositive colloid, $\mathrm{Cr}(\mathrm{OH})_{3}$ $\mathrm{Cr}(\mathrm{OH}) \mathrm{CrO}_{4}$.

3. Fink (11) advanced a theory in which the sulphate is designated as a catalyst, but he gave no clear conception of its action. $\mathrm{He}$ assumed that the hydrogen that is always evolved in chromium deposition protects the metal from oxidation.

4. E. Müller (14) recognized that pure chromic acid is not reducible at high current densities. He attributed this fact to the formation of a colloidal layer in the slightly acid cathode film as a result of the migration of an electropositive sol. The idea that the cathode layer is permeable to hydrogen ions was expressiy set forth. His first explanation of the action of the sulphate was that it precipitated and destroyed the cathode layer, and thus made possible the reduction of chromic acid. Later (20), (21), (24), and (33) he abandoned this interpretation in favor of one which states that the bisulphate ion, $\mathrm{HSO}_{4}^{-}$, can, on account of its relatively small size, pass through interstices in the colloidal layer, thus permitting the existence of a higher hydrogen ion concentration in the cathode film. This condition is less favorable for the formation of the basic colloid. It is important to note that he found it necessary to assume that the bisulphate ion is effective at a pH of 3 or 4 , and that its attraction toward the cathode is secondary. Müller demonstrated that the basic dispersoid, $\mathrm{Cr}(\mathrm{OH})_{3} \mathrm{Cr}(\mathrm{OH}) \mathrm{CrO}_{4}$, is electropositive. This theory is somewhat similar to that developed in this paper.

5. Haring (13), (17), and later Piersol (27) suggested that the action of the sulphate is in accordance with the following equation:

$$
\begin{aligned}
& \mathrm{Cr}_{2}\left(\mathrm{Cr}_{2} \mathrm{O}_{7}\right)_{3}+3 \mathrm{H}_{2} \mathrm{SO}_{4} \rightarrow \mathrm{Cr}_{2}\left(\mathrm{SO}_{4}\right)_{3}+3 \mathrm{H}_{2} \mathrm{Cr}_{2} \mathrm{O}_{7} \\
& \text { (colloid) (strong (strong (strong } \\
& \text { electro- electro- electro- } \\
& \text { lyte) lyte) lyte) }
\end{aligned}
$$


Chromium dichromate is not a colloid, and a pure metathesis (like the one represented) between a slightly soluble (or ionizable) salt and a strong electroly te to produce two strong electrolytes in dilute solution is thermodynamically impossible.

6 . Ollard's (22) theory denies that chromic acid can be reduced directly, and states that all reduction must proceed through the medium of the chromic-chromous couple. The action of the sulphate was explained by a reaction similar to that proposed by Haring and Piersol except that chromium dichromate was considered to be a very weak electrolyte.

7. In this research a theory of chromium deposition has been developed, which involves some features that have been expressed in previous theories, but that have been modified in the light of additional information and of a different viewpoint.

Deposition of bright chromium depends upon maintaining in the cathode film a definite hydrogen ion concentration. This must be sufficiently low to permit metal deposition and yet sufficiently high to prevent hydrolysis and thus yield oxide-free deposits.

At low current densities direct reduction of hexavalent to trivalent chromium undoubtedly occurs. At high current densities, which require cathode potentials sufficient to liberate hydrogen gas, the conditions are vastly different. On account of the tremendous migration velocity of the hydrogen ion in the cathode film, the latter becomes relatively alkaline. If the hydrogen ion concentration drops to $10^{-3}$, a basic electropositive dispersoid of $\mathrm{Cr}(\mathrm{OH})_{3} \cdot \mathrm{Cr}(\mathrm{OH}) \mathrm{CrO}_{4}$ exists. In the absence of the sulphate the dispersoid migrates toward the cathode and covers it with a colloidal layer which prevents reduction of everything except hydrogen ion, to which it is permeable.

The action of the sulphate is to decrease the electrophoretic velocity of the colloid by adsorption; which causes a reduction of the positive charge and prevents the formation of a dense, adherent colloidal layer. Other ions can then reach the cathode and be reduced. It is improbable, on account of the repulsive action of the cathode toward negative ions, that the simple sulphate ion can approach the cathode sufficiently close to be very effective. Some other means must be found for bringing it to the cathode.

It is well known that ordinary green chromic sulphate forms nondissociable, positive molecular ions like $\left[\mathrm{Cr}_{4} \mathrm{O}\left(\mathrm{SO}_{4}\right)_{4}\left(\mathrm{H}_{2} \mathrm{O}\right)_{\mathrm{n}}\right]^{++}$. This ion can, on account of its nonreactiveness, convey the sulphate to the cathode surface, and when the complex ion is discharged and reduced, the sulphate is set free to wander toward the anode. Before leaving the vicinity of the cathode, it may be adsorbed by the positive dispersoid and may thus limit the formation of the colloidal layer. While reduction at high current densities is made possible by the presence of sulphate, the actual reduction occurs mainly through the chromic-chromous couple.

\section{POSSIBLE REDUCTION PROCESSES}

It will be profitable to examine the principal reactions in terms of their standard electrode potentials (4). It will be seen that the conditions that are required for chromium deposition are those that inhibit certain undesirable reactions. 
TABLE 9.-Standard potentials of possible reactions in chromium deposition

\begin{tabular}{|c|c|c|}
\hline No. & Reaction & $\begin{array}{l}\text { Standard } \\
\text { potential }\end{array}$ \\
\hline 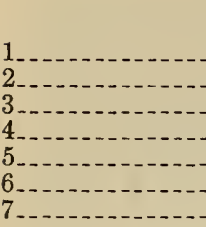 & 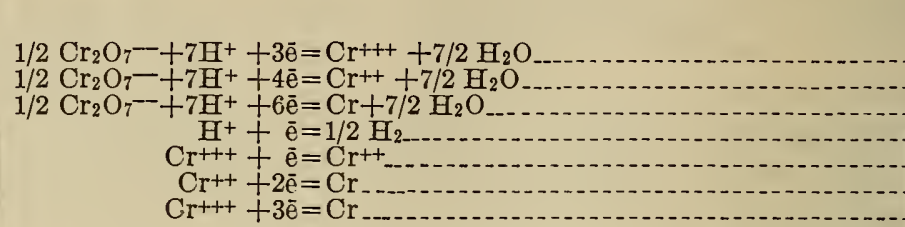 & $\begin{array}{r}\text { Volts } \\
1.3 \\
.9 \\
.4 \\
.0 \\
-.4 \\
-.5 \\
-.5\end{array}$ \\
\hline
\end{tabular}

$\overline{\mathrm{e}}$ denotes an electron.

According to reaction 3 , it should be theoretically possible to arrange a cell having a chromium-coated metal as cathode and a hydrogen electrode as anode, and deposit chromium without the use of external electrical energy. In fact, there would be a gain of electrical energy that could be employed to generate some of the hydrogen used. The reason that this is impracticable is because reaction 1 is the more probable under any condition that is favorable for reaction 3 . If instead of chromic acid a chromic salt were employed electrical energy would be required in order to effect chromium deposition.

\section{REACTIONS IN THE CATHODE FILM}

During deposition at appreciable current densities the solution close to the cathode, the cathode film, may differ greatly in composition from the body of the solution. However, a steady state is set up between the factors causing depletion and restoration of the various species in the film. The former include, first, the rates of discharge of the various ions present, and, second, the forces that exist between the ions and the cathode. The restorative factors include, first, migration of the ions toward the cathode, second, diffusion processes and, third, convection currents. The electrical forces very close to the cathode are relatively large and hence there is a large concentration gradient in the cathode film. The processes that actually occur at the cathode under specified conditions depend upon the composition and structure of the cathode film.

There are three imperative reasons why the cathode film must possess an intermediate $\mathrm{pH}$ ( 3 or 4 ) before deposition of metallic chromium can occur. First, the difference in free energy between the standard chromium-chromic ion potential and the standard hydrogen-hydrogen ion potential is 0.5 volt faraday per equivalent. This demands, first, that the hydrogen ion concentration be low for chromium to be deposited, although the permissible hydrogen ion concentration will be conditioned by the hydrogen overvoltage. Second, it must not be too low because the chromic ion is easily hydrolyzed and, if the film becomes too basic, oxides or basic compounds will be deposited. Third, in the reduction of chromic acid large amounts of oxygen are converted to oxygen ions or hydroxyl ions, which must be neutralized by hydrogen ions to prevent the formation of oxides and hydroxides.

If pure chromic acid is electrolyzed at such low current densities that the cathode potential is not sufficient to cause hydrogen evolution, the cathode film will have a higher hydrogen ion concentration than the solution. Under these conditions true undissociated mole- 
cules of chromic acid can exist close to the cathode and may be reduced directly by the electrons to the trivalent state. The formation of metallic chromium is possible but improbable with the acidic conditions obtaining.

If the cathode potential and current density are raised so that hydrogen is discharged the conditions are vastly different. The hydrogen ion concentration in the cathode film tends to drop very rapidly on account of the tremendous migration velocity of the hydrogen ion within the film. The decrease in hydrogen ion concentration is favorable to the deposition of chromium, especially as large amounts of trivalent chromium must have been formed before this condition could arise. Reactions, 1, 2, and 3 show that the direct reduction of chromic acid will be tremendously affected by a variation in the hydrogen ion concentration. This leads to the conclusion that with increasing current density the chromic-chromous couple becomes the dominant process in effecting the reduction of chromic acid. This couple consists of having chromic ion reduced at the cathode to the chromous ion, which on escaping into the body of the solution reduces chromic acid to trivalent chromium. There is no justification for the suggestion that cathodic reduction is effected by atomic hydrogen. Such a process is in direct conflict with thermodynamic principles.

It has been shown above that when this system attains a hydrogen ion concentration of $10^{-3}$, a sol of the basic chromium chromate, $\mathrm{Cr}(\mathrm{OH})_{3} \cdot \mathrm{Cr}(\mathrm{OH}) \mathrm{CrO}_{4}$, exists. This sol and any other form of the colloid are probably permeable to hydrogen ions, in view of the fact that in migration and diffusion the radius of the bare hydrogen ion is effective and not that of the hydrated or hydronium ion. The chain theory (30) of the abnormally high migration velocity of the hydrogen ion indicates that although the colloid may permit hydrogen ions to pass through, it will hamper their motion. By this action the portions closer to the cathode will possess a still lower hydrogen ion concentration.

The amount of the colloid formed and the particle size will vary inversely, whereas the electrophoretic velocity will vary directly as the hydrogen ion concentration. The Brownian movement of the dispersoid of the sol, and hence the permeability of the sol, is greatest at the highest hydrogen ion concentration consistent with its existence. However, the high electrophoretic velocity under these conditions favors the formation of the colloidal layer, which would tend to exclude all ions but hydrogen and thus prevent reduction. As shown elsewhere in this paper the amount of colloid varies very rapidly with the hydrogen ion concentration, whereas the electrophoretic velocity does not vary in the range probably involved. No change in conditions is to be expected by varying the hydrogen ion concentration in the cathode film by means of the current density. It appears from this analysis that the formation of the objectionable colloidal layer is a precipitative effect and that any explanations of the beneficial action of the sulphate on the basis of a similar effect is illogical.

\section{ACTION OF NEGATIVE IONS, SUCH AS SULPHATE}

Müller's first theory that the sulphate coagulates the colloid and thus destroys the colloid layer is untenable because the resultant precipitate would probably hinder the reduction as completely as the 
original sol. He abandoned this view in favor of one which states that the particles of the sol tend to arrange themselves in a more or less regular manner on the surface of the cathode. In consequence, there will be spaces with a certain average size through which relatively small negative ions may pass. This condition permits the existence of a higher hydrogen ion concentration at the cathode surface and is less favorable to the formation of the colloid.

A number of criticisms have been leveled against the conception of colloids and colloidal layers in chromium deposition. It is important to note that the sol is only a part of the cathode film; though it may under certain conditions constitute almost exclusively a definite section of it; that is, the colloidal layer. The colloidal layer and the sol are stable because the cathode film is low in hydrogen ions. The supposed difficulty of the discharged hydrogen breaking up the colloidal layer and destroying the film structure does not exist because the cathodic processes discussed are microscopic and not macroscopic. The rates of the reactions involved are undoubtedly much faster than bubble formation; furthermore, bubble formation would not involve the destruction of the film.

If electrophoretic migration is important in determining the reduction processes, adsorption is also. Since the sol is electropositive, the adsorbable ions must be negative. Theories of the structure of the cathode film (31) indicate that close to the cathode there is a paucity of negative ions, because they are repelled by the cathode. This is the most important region, hence means must be found for bringing negative ions into this forbidden territory.

The question naturally arises as to why the dichromate ion, $\mathrm{Cr}_{2} \mathrm{O}_{7}^{--}$, is ineffective (chromate ion, $\mathrm{CrO}_{4}^{--}$, does not exist at a $\mathrm{pH}$ of 3 or 4 ). Being a negative divalention, it could be adsorbed by the sol and thus alter the electrophoretic velocity. It is admitted that this effect does exist in the outer fringes of the film, but apparently not close to the cathode proper. Only high-energy negative ions can penetrate the repulsive barrier and be adsorbed by the electropositive sol. It has been demonstrated above that chromium dichromate does not exist in the green form and hence does not form positive molecular ions like $\left[\mathrm{Cr}\left(\mathrm{Cr}_{2} \mathrm{O}_{7}\right)\left(\mathrm{H}_{2} \mathrm{O}\right)_{4}\right]^{+}$, which on account of their nonreactive nature would be able to penetrate the film. Even if it were so conveyed, the dichromate would be reduced at the cathode and hence become ineffective. An effective addition agent must be nonreducible. The nonexistence of the "green" form of the dichromate favors, however, the formation of oxide-free deposits.

The action with the sulphate is vastly different. In consequence of its small size and high charge it will be readily adsorbed by the electropositjve sol. It readily forms green complexes with trivalent chromium in which the sulphate is in an extremely nonreactive, positive molecular ion, possibly $\left[\mathrm{Cr}_{4} \mathrm{O}\left(\mathrm{SO}_{4}\right)_{4}\left(\mathrm{H}_{2} \mathrm{O}\right)_{n}\right]^{++}$. This ion is capable of passing through the "forbidden" territory with little change. On reaching the cathode surface the ion is reduced so that the chromium is no longer trivalent and the sulphate ion is set free. While still in the cathode film it may either first, reform the green complex (which is improbable at the $\mathrm{pH}$ prevailing); second, exist in the free state (a possibility already demonstrated in this paper); or, third, it may be adsorbed by the particles of the sol. This latter action will lower the 
electrophoretic velocity, and render the formation of a dense collodial layer improbable. The action of the chloride would be similar. The positive molecular ions that would then be effective are undoubtedly $\left[\mathrm{CrCl}\left(\mathrm{H}_{2} \mathrm{O}\right)_{5}\right]^{++}$and $\left[\mathrm{CrCl}_{2}\left(\mathrm{H}_{2} \mathrm{O}\right)_{4}\right]^{+}$.

Evidence of the relative adsorption of ions by basic chromium chromate was obtained in migration experiments reported in Table 10. A suspensoid of the basic chromate, $\mathrm{Cr}(\mathrm{OH})_{3} \mathrm{Cr}(\mathrm{OH}) \mathrm{CrO}_{4}$, was prepared by grinding a precipitate in a colloid mill until the particles were of the order of $1 \mu$. The migration apparatus was of the type used by Abramson and Freundlich (16). Electrode effects were rendered negligible by having nonpolarizable electrodes. The electroendosmose effect was eliminated in the manner advocated by Smoluchowski (8). Relative values only are reported, as absolute measurements were impracticable with the apparatus employed. Either sodium or potassium salts were used.

TABLE 10.-Relative electrophoretic velocit,es of basic chromate in the presence of added ions at $25^{\circ} \mathrm{C}$.

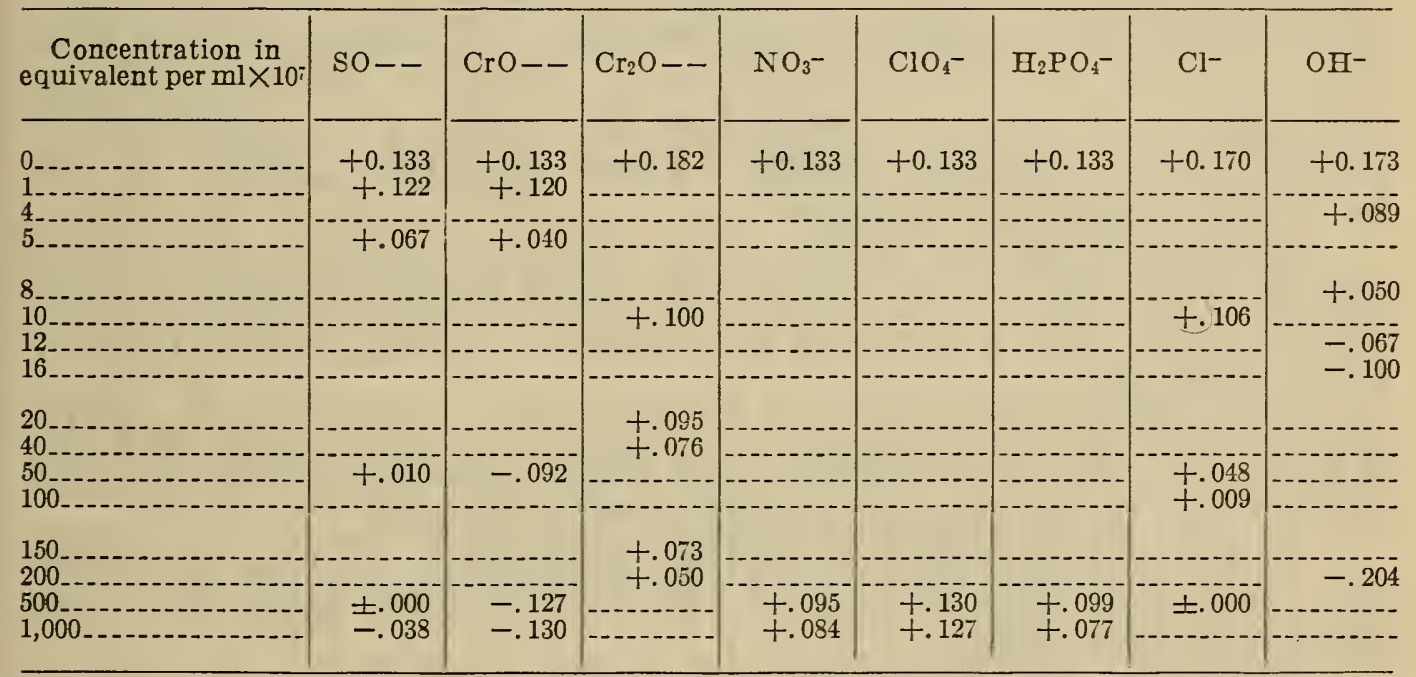

It is obvious that three ions are outstanding in their adsorption; namely, the sulphate, chromate, and hydroxide. The effects of the latter two ions are undoubtedly specific, since we are dealing with a basic chromate. At a pH of 3 or 4 neither chromate nor hydroxide ions can exist in significant concentrations, hence they are unimportant in the cathode film. The dichromate and the chloride are adsorbed to about the same extent, but only the chloride is an effective addition agent. This difference must be due to the fact that the green form of chromic chloride exists, whereas that of chromic dichromate does not. The perchlorate ion is much less adsorbed than the nitrate or phosphate.

$\mathrm{pH}$ measurements with the glass electrode were made on solutions with hydroxide additions. It was established that the isoelectric point occurred at a $\mathrm{pH}$ of about 6 . The maximum electropositive velocity was attained at a $\mathrm{pH}$ of 4.5 and remained constant with a further decrease in $\mathrm{pH}$. The maximum electronegative velocity was attained at 7 and did not change with a further increase in $\mathrm{pH}$. 


\section{CONCLUSIONS}

(a) The processes of reduction at low and high current density are different.

(b) Metal deposition from the chromic acid bath depends on maintaining a definite $\mathrm{pH}$ in the cathode film.

(c) At high current densities pure chromic acid can not be reduced owing to the formation of a colloidal layer.

(d) The action of the sulphate is to lower the electrophoretic velocity of the particles of the sol and thus render the formation of a dense adherent layer improbable.

(e) The sulphate is effective because it is a negative ion that is nonreducible and strongly adsorbable, and that forms positive molecular ions with trivalent chromium.

\section{APPLICATIONS OF THE PROPOSED THEORY}

The utility of the proposed theory was tested by explaining the principal known facts of chromium deposition, and by making predictions that were verified experimentally. The data used in these considerations were derived principally from the curves of Haring and Barrows (17) and of Farber and Blum (25), whose experimental conditions were clearly defined. These data refer chiefly to the 2.5 $M$ solutions of chromic acid.

1. The sulphate ion is the most effective addition agent tried. This is to be expected in view of the fact it forms positive molecular ions with trivalent chromium and that it is highly adsorbed by the basic chromate.

2. The effect of the sulphate is independent of the form in which it is added. This follows from the theory which involves only the sulphate ion or its complex with trivalent chromium.

3. A low concentration of sulphate is effective. This is in accordance with adsorption phenomena and with the migration experiments recorded in this paper.

4. The curve for the sulphate concentration versus the cathode efficiency passes through a maximum. The increase in the cathode efficiency up to the maximum represents the favorable effect of the sulphate in preventing the formation of a dense colloidal layer on the cathode. Beyond the maximum the adsorption is so great as to produce excessively large colloidal particles with a sluggish Brownian movement. This feature decreases the permeability and hence the efficiency. At the isoelectric point a colloidal layer is formed through precipitation. The deposits produced with excess sulphate are usually nonadherent, owing probably to the precipitated colloid. The beneficial action of the sulphate occurs on the positive side of the isoelectric point. ${ }^{7}$

5. At higher current densities the curve for the sulphate concentration versus the cathode efficiency becomes flatter. This is because at the higher current densities more colloid is formed and the effect of a given increase in sulphate content is proportionally less.

6. At higher temperatures the sulphate content is less critical, as was shown by Willink (32). This is because the sulphate is then not so strongly adsorbed, which tends to make the curve of current

7 Compare Frölich (15); 
efficiency versus sulphate concentration broad and similar to that obtained with the fluoride at lower temperatures. A higher concentration of sulphate is probably necessary in order to realize the maximum efficiency.

7. The curve for fluoride concentration versus cathode efficiency has a long flat maximum, in contrast to the sharp maximum of the sulphate curve. The adsorption of the divalent sulphate ion will be much greater than that of monovalent ions, such as fluoride and chloride. No electrophoretic measurements were made on the effect of the fluoride, but it is probably similar to that of the chloride. On this basis the difference in behavior can be explained.

8. The acetate ion is ineffective. Acetates and other organic anions do not form green chromic complexes.

9. The nitrate ion is ineffective. Carvath and Curry (1) reported that it produces black deposits with low efficiencies. The nitrate does not form green complexes under the conditions that obtain in these solutions and is not readily adsorbed by the sol.

10. According to Müller phosphates are completely ineffective. While the dihydrogen phosphate ion is adsorbed at least as much as the nitrate, chromium phosphate is very insoluble at the $\mathrm{pH}$ of the cathode film.

11. Perchlorate is ineffective according to Müller's polarization curves. As this is a stable radical it would appear ideal according to the theories of Haring, Ollard, and Piersol. However, the green form of chromium perchlorate does not exist, and the perchlorate ion is only slightly adsorbed; hence, according to the theory presented in this paper, it is ineffective. This was confirmed by numerous experiments. In all cases a brown powder or no deposit was obtained and the metal efficiencies were very low (compare (33)). The solutions contained 2.5 $\mathrm{MCrO}_{3}$ and from 0.1 to $1 \mathrm{MHClO}_{4}$, the current densities ranged from 10 to $50 \mathrm{amp} . / \mathrm{dm}^{2}$, and the temperature was $45^{\circ} \mathrm{C}$.

12. Pure chromic acid can be reduced to trivalent chromium at low but not at high current densities. This is because at low current densities the chromium compounds have access to the cathode, while at high current densities the semipermeable colloidal layer prevents reduction.

13. As the concentration of chromic acid is increased, the cathode efficiency is decreased. In view of the fact that the chromic ion is less readily reduced and slower than the hydrogen ion, the hydrogen ion concentration in the cathode film will be the most sensitive factor dependent on the rate of supply. With a greater concentration of acid in the body of the solution, the hydrogen ion concentration in the film will be greater, and hence the efficiency will be less.

14. The cathode efficiency does not change greatly if the acidity is decreased by neutralizing part of the chromic acid with alkali. This conclusion (Farber and Blum) is in apparent contradiction with No. 13. The two cases are not strictly comparable. In this case the slower and less reducible positive ion (sodium) would permit a larger concentration of dichromate ions to exist in the cathode film, and cause an even lower hydrogen jon concentration than would be expected on the basis of lowering the free acid. Apparently what occurs is that this condition favors the formation of excessive amounts of the colloid, which 
counteracts the increase in efficiency due to lowering the hydrogen ion concentration.

15. At $25^{\circ} \mathrm{C}$. the bright plating range is decreased by an increase in the trivalent chromium content (18). This behavior is readily explained by the theory. It was also predicted that this effect could be counteracted by an addition of sulphate. The trivalent chromium increases the cathode efficiency, but also increases the colloid formation at the cathode, especially at high current densities. By adding sulphate this effect should be eliminated. This was confirmed by experiments with $2.5 \mathrm{M} \mathrm{CrO}_{3}$ in which the presence of about $N$ trivalent chromium required an increase of sulphate from $0.05 N$ to $0.15 N$ to widen the plating range.

16. The cathode efficiency increases with an increase in current density. This is because at the higher current density the hydrogen evolution is greater (absolutely but not relatively) and hence the cathode film becomes less acid, and a higher potential is required for hydrogen evolution, which factor favors a higher efficiency for the reduction of chromic acid.

17. A still further increase in current density produces "burnt" deposits. These contain oxides derived from the hydrolysis of the chromic ion when the hydrogen ion concentration in the cathode film is too low.

18. The cathode efficiency decreases with an increase in temperature. The hydrogen overvoltage decreases with increase in temperature, and hence hydrogen evolution is increased. This effect partially results from the more rapid convection with increasing temperature, which brings a larger supply of chromic acid into the cathode film and increases the hydrogen ion concentration.

19. Although many of the factors that give rise to the widened plating range at higher temperatures are beyond the theory presented, there is one important factor that can be accounted for. The shift of the plating range at higher temperatures to higher current densities is due to the fact that then a higher current density is necessary to yield the intermediate hydrogen ion concentration necessary for chronium deposition.

20. The initial cathode efficiency is highest on metals with the highest hydrogen overvoltage. This feature is strictly beyond the theory, but is consistent with it.

A number of other features of the process have been analyzed by means of the theory and explained. Only those that are regarded as the most outstanding have been reported.

\section{ACKNOWLEDGMENTS}

Appreciation is extended to W. Blum for his suggestion of the problem, his ever available assistance, and his able counsel. M. R. Thompson kindly made the $\mathrm{pH}$ measurements that disclosed important relationships.

\section{BIBLIOGRAPHY}

1. H. R. Carveth and B. E. Curry, J. phys. chem., vol. 9, p. 353, 1905.

2. N. Bjerrum, Z. physik. chem., vol. 59, p. 596, 1907.

3. N. Bjerrum, Z. anorg: chem., vol. 63, p. 140, 1909.

4. R. Abegg, F. Auerbach and R. Luther, Abhandlungen der Deutschen Bunsengesellschaft No. 5 Halle, 1911.

5. A. Hantszch and P. Garrett, Z. physik. chem., vol. 84, p. 321, 1913. 
6. G. J. Sargent, Trans. Am. Electrochem. Soc., vol. 37, p. 479, 1920.

7. R. Abegg, Handbuch der Anorganischen Chemie, Band IV, 1921.

8. M. Smoluchowski in Gratz, Handbuch der Elektrizität, Band II, p. 366, 1921:

9. E.' Liebreich, Z. Elektrochem., vol. 27, pp. 94, 452, 1921.

10. E. Liebreich, Z. Elektrochem., vol. 29, p. 208, 1923.

11. C. G. Fink, United States Patent, 1581188, 1925.

12. Opt. Soc. Am., vol. 10, p. 169, 1925.

13. H. E. Haring, Chem. Met. Eng., vol. 32, p. 692, 1925.

14. E. Müller, Z. Elektrochem., vol. 32, p. 399, 1926.

15. P. K. Frölich, Trans. Am. Electrochem. Soc., vol. 69, p. 395, 1926.

16. H. Freundlich and H. A. Abramson, Z. physik. chem., vol. 126, p. 25, 1927.

17. H. E. Haring and W. P. Barrows, B. S. Tech. Paper No. 346, 1927.

18. R. Schneidewind, Univ. Michigan Eng. Res. Bull., No. 10, 1928.

19. D. T. Ewing, J. O. Hardesty, and T. H. Kao, Bull. No. 19, Michigan Eng. Exper. Station, 1928.

20. E. Müller and P. Eckwall, Z. f. Elektrochem., vol. 35, p. 84, 1929.

21. E. Müller and I. Stscherbakow, Z. f. Elektrochem., vol. 35, p. 222, 1929.

22. E. A. Ollard, Electroplaters' and Depositors' Tech. Soc., vol. 3, p. 5, 1929.

23. S. Freed and C. Kasper, J. Am. Chem. Soc.; vol. 52, p. 2632, 1930.

24. E. Müller and O. Essin, Z. Elektrochem., vol. 36, p. 2, 1930.

25. H. L. Farber and W. Blum, B. S. Jour. Res., vol. 4, p. 27, 1930.

26. H. R. Moore and W. Blum, B. S. Jour. Res., vol. 5, p. 255, 1930.

27. R. J. Piersol, Metal Cleaning and Finishing, vol. 3, p. 207, 1931.

28. R. W. Wyckoff, Structure of Crystals, 2d ed., Chem. Catalogue Co., 1931.

29. L. Pauling, J. Am. Chem. Soc., vol. 53, p. 1396, 1931.

30. M. Huggins, J. Am. Chem. Soc., vol. 53, p. 3190, 1931.

31. R. W. Gurney, Proc. Roy. Soc., vol. 134A, p. 137, 1931.

32. A. Willink, Trans. Electrochem. Soc., preprint 61-5, 1932.

33. E. Müller, Z. Elektrochem., vol. 38, p. 205, 1932.

34. B. Lange, Z. physik. chem., vol. A 159, p. 277, 1932.

WASHington, July 6, 1932. 